\title{
Oesophagogastric intussusception associated with spirocercosis in a dog
}

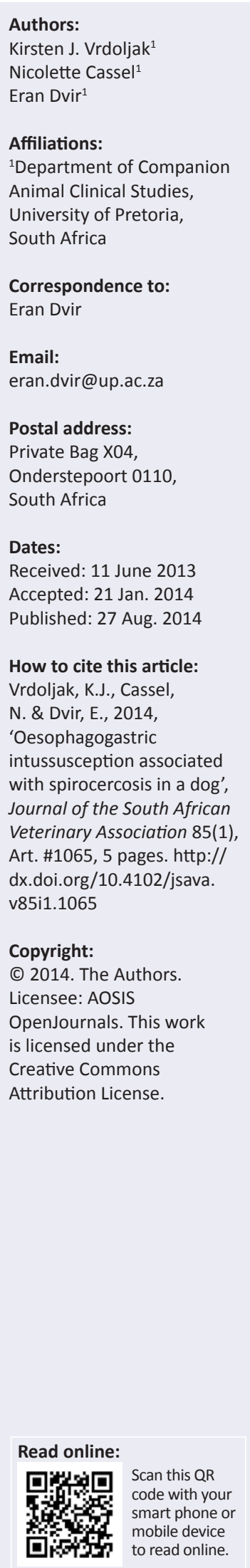

An oesophagogastric intussusception was diagnosed in an intact Bull Terrier female aged 2 years and 7 months with a concurrent Spirocerca lupi infection. The dog was presented collapsed with a history of inappetance and lethargy of one day's duration. Anaemia and melaena were present on clinical examination. Thoracic radiographs did not reveal any significant findings. Abdominal ultrasound was suspicious for gastric pathology or a possible foreign body. The final diagnosis of an oesophagogastric intussusception with an S. lupi nodule at the cardia was made on post-mortem. Oesophageal intussusceptions are rare in dogs and often fatal. Gastro-oesophageal intussusceptions usually present with obvious radiographic signs in the caudal thorax, unlike an oesophagogastric intussusception, where the pathology lies within the abdomen and may not be readily diagnosed. Although spirocercosis often presents with a caudal oesophageal mass, this may not be seen radiographically. In this case, the two conditions were present together but the thoracic radiographs were normal.

\section{Introduction}

This case represents a very unusual occurrence of spirocercosis that presented as an oesophagogastric intussusception. The clinical signs reported in canine spirocercosis depend on the location and the severity of the lesions (Mazaki-Tovi et al. 2002). The clinical signs associated with spirocercosis include: vomiting or regurgitation, weight loss, pyrexia, respiratory abnormalities, enlarged salivary glands, melaena and locomotor deficits (Dvir et al. 2008; Fox, Burns \& Hawkins 1988; Mazaki-Tovi et al. 2002). Apart from rare, sudden death due to aortic rupture, the presenting signs are normally slowly progressive (Van der Merwe et al. 2008). Diagnosis in the early stages of infection may be difficult and often animals are only presented when oesophageal involvement is seen. The non-specific clinical signs of infection make the diagnosis challenging; additional modalities such as radiology, endoscopy and computed tomography are often required. Initial diagnosis of a suspected Spirocerca lupi nodule is most commonly made radiographically (Dvir, Kirberger \& Malleczek 2001). Radiological diagnosis is based on the presence of a caudal oesophageal mass with possible concurrent caudal thoracic spondylitis and aortic aneurysms (presented as aortic undulation) (Mazaki-Tovi et al. 2002). Whilst thoracic spondylitis and aortic undulation are considered to be pathognomonic for spirococercosis, a caudal oesophageal mass has a few differential diagnoses that include gastro-oesophageal intussusception.

Gastro-oesophageal intussusception is described as the invagination of the stomach into the lumen of the thoracic oesophagus (Rallis, Moraitou \& Vlemmas 1995). It is an uncommon and often fatal condition in dogs and is defined as an acute emergency problem that requires immediate surgical reduction. It follows that an oesophagogastric intussusception is described as the invagination of the oesophagus into the stomach. Although cases of gastro-oesophageal and pylorogastric intussusceptions have been reported, to the best of the authors' knowledge, there is no published information on oesophagogastric intussusceptions in dogs. The clinical signs of gastro-oesophageal intussuception include: vomiting or regurgitation, dyspnoea, haematemesis and abdominal discomfort (Leib \& Blass 1984; Von Werthern, Montavon \& Fluckiger 1996). There is often a rapid deterioration of clinical signs and subsequent death (Von Werthern et al. 1996). Radiographic evidence of a gastro-oesophageal intussusception includes a large soft-tissue mass in the caudal mediastinum. Commonly, a gas-filled, dilated oesophagus is visible cranial to the herniation and the intussuscepted portion of the stomach appears as a mass within the oesophageal lumen. Rugal folds may be recognised on the surface of the mass, especially when barium is present within the oesophagus. A stomach silhouette may be absent from the cranial abdomen (Watrous 2007). Radiographic evidence of an oesophagogastric intussusception has not been described. Predisposing factors to the formation of gastro-oesophageal intussusception include: idiopathic megaoesophagus, incompetency of the lower oesophageal sphincter and vomiting (Graham et al. 1998; Leib \& Blass 1984; Rallis et al. 1995; Von Werthern et al. 1996).

One case of gastro-oesophageal intussusception due to $S$. lupi has previously been described (Rallis et al. 1995). An S. lupi nodule was found very close to the cardia in an intact 6-year-old 
male German Shepherd dog. It was hypothesised that the nodule produced a mechanical or functional aberration of the lower oesophageal sphincter tone, which provoked lower oesophageal sphincter relaxation, resulting in invagination of the stomach and duodenum into the lumen of the oesophagus. It was thought that $S$. lupi provoked oesophageal neuromuscular degeneration resulting from chronic inflammation caused by the parasite and asynchronous relaxation of the lower oesophageal sphincter (Rallis et al. 1995).

This communication provides details of a case of oesophagogastric intussusception with a concurrent S. lupi nodule at the cardiac sphincter. The difficulties involved in the diagnosis of this case are discussed.

\section{Case history}

A 2-year-and-7-month-old intact female Bull Terrier presented at the Onderstepoort Veterinary Academic Hospital (OVAH); she collapsed on arrival. According to the owners, the dog had been lethargic and inappetant for a day. The owners thought that the dog may have eaten a blanket. There was no history of any vomiting or diarrhoea.

On clinical examination, the dog was tachycardic $(160 \mathrm{bpm}$, reference range $80 \mathrm{bpm}-100 \mathrm{bpm})$, with pale mucous membranes and a tense abdomen on palpation. A rectal examination revealed soft melaena.

On initial presentation, the dog was severely anaemic (Ht of $12 \%$ ) with mildly increased lactate (Table 1). Haematology revealed a severe normocytic, normochromic anaemia (Table 2). Although the reticulocytes were not counted, there was some evidence of regeneration, with a red cell distribution width of $16.5 \%$, anisocytosis, polychromasia and a normoblast count of $8 \%$. The dog had concurrent mild thrombocytopaenia with marked leukocytosis due to marked regenerative left shift neutrophilia. Total protein was mildly decreased with moderate hypoalbuminaemia (Table 3). Sodium, potassium and total calcium were all mildly decreased. There was a mild increase in urea and the urine was haemoglobinuric. Faecal flotation revealed no sign of helminths.

Gastric ulceration was suspected and packed red cells were administered along with Ampicillin at $20.0 \mathrm{mg} / \mathrm{kg}$ three times a day, Omeprazole at $0.7 \mathrm{mg} / \mathrm{kg}$ once a day and Sucralfate at $1.0 \mathrm{~g}$ twice a day. The pack cell volume after the transfusion had increased to $17 \%$ and the dog's habitus and vital signs were mildly improved the next morning. Melaena and haemoglobinuria were still present.

On abdominal ultrasound, the spleen was slightly mottled, the bladder contained a moderate amount of hyperechoic sludge and the stomach was moderately distended with heterogeneously hyperechoic luminal content typical for ingesta. In the region of the cardia and extending into the
TABLE 1: Initial findings.

\begin{tabular}{lll}
\hline Test value & Patient values & Normal values \\
\hline Pack cell volume & 0.12 & $0.37 \mathrm{~L} / \mathrm{L}-0.55 \mathrm{~L} / \mathrm{L}$ \\
Total serum protein & 44.00 & $53 \mathrm{~g} / \mathrm{L}-75 \mathrm{~g} / \mathrm{L}$ \\
Glucose & 6.20 & $3.5 \mathrm{mmol} / \mathrm{L}-5.5 \mathrm{mmol} / \mathrm{L}$ \\
Lactate & 2.50 & $<1.5 \mathrm{mmol} / \mathrm{L}$ \\
Creatinine & 44.00 & $40 \mathrm{umol} / \mathrm{L}-133 \mathrm{umol} / \mathrm{L}$ \\
\hline
\end{tabular}

TABLE 2: Haematological findings.

\begin{tabular}{|c|c|c|}
\hline Test value & Patient values & Normal values \\
\hline Haemoglobin & 36.00 & $120 \mathrm{~g} / \mathrm{L}-180 \mathrm{~g} / \mathrm{L}$ \\
\hline Red cell count & 1.55 & $5.50 \times 10 \mathrm{e}^{12} / \mathrm{L}-8.50 \times 10 \mathrm{e}^{12} / \mathrm{L}$ \\
\hline Haematocrit & 0.10 & $0.37 \mathrm{~L} / \mathrm{L}-0.55 \mathrm{~L} / \mathrm{L}$ \\
\hline White cell count & 24.50 & $6.0 \times 10 e^{9} / L-15.0 \times 10 e^{9} / L$ \\
\hline $\begin{array}{l}\text { Neutrophils (mature) } \\
\text { absolute }\end{array}$ & 16.42 & $3.00 \times 10 \mathrm{e}^{9} / \mathrm{L}-11.00 \times 10 \mathrm{e}^{9} / \mathrm{L}$ \\
\hline $\begin{array}{l}\text { Neutrophils (immature) } \\
\text { absolute }\end{array}$ & 5.15 & $0.00 \times 10 \mathrm{e}^{9} / \mathrm{L}-0.50 \times 10 \mathrm{e}^{9} / \mathrm{L}$ \\
\hline Lymphocytes absolute & 1.72 & $1.00 \times 10 \mathrm{e}^{9} / \mathrm{L}-4.80 \times 10 \mathrm{e}^{9} / \mathrm{L}$ \\
\hline Monocytes absolute & 1.23 & $0.15 \times 10 \mathrm{e}^{9} / \mathrm{L}-1.35 \times 10 \mathrm{e}^{9} / \mathrm{L}$ \\
\hline Eosinophils absolute & 0.00 & $0.10 \times 10 \mathrm{e}^{9} / \mathrm{L}-1.25 \times 10 \mathrm{e}^{9} / \mathrm{L}$ \\
\hline Basophils absolute & 0.00 & $0.0 \times 10 \mathrm{e}^{9} / \mathrm{L}-0.1 \times 10 \mathrm{e}^{9} / \mathrm{L}$ \\
\hline Platelets & 114.00 & $200 \times 10 e^{9} / L-500 \times 10 e^{9} / L$ \\
\hline Anisocytosis & $4+$ & - \\
\hline Polychromasia & $2+$ & - \\
\hline Spherocytes & Few & - \\
\hline Normoblast & $8 \%$ & - \\
\hline $\begin{array}{l}\text { Red cell distribution } \\
\text { width }\end{array}$ & 16.50 & $\begin{array}{l}<16.25 \text { indicates } \\
\text { non-regenerative anaemia }\end{array}$ \\
\hline Platelet smear & $\begin{array}{l}\text { Platelet aggregation } \\
\text { number low }\end{array}$ & - \\
\hline Parasites & No parasites seen & - \\
\hline
\end{tabular}

TABLE 3: Biochemistry findings.

\begin{tabular}{lll}
\hline Test value & Patient values & Normal values \\
\hline Total protein & 48.30 & $(53.0 \mathrm{~g} / \mathrm{L}-75.0 \mathrm{~g} / \mathrm{L})$ \\
Albumin & 18.30 & $(27.0 \mathrm{~g} / \mathrm{L}-35.0 \mathrm{~g} / \mathrm{L})$ \\
Globulin & 29.90 & $(20.0 \mathrm{~g} / \mathrm{L}-37.0 \mathrm{~g} / \mathrm{L})$ \\
Albumin and Globulin ratio & 0.61 & $(0.60-1.20)$ \\
Alanine transaminase & 40.00 & $(9 \mathrm{U} / \mathrm{L}-73 \mathrm{U} / \mathrm{L})$ \\
Alkaline phosphatase & 135.00 & $(65 \mathrm{U} / \mathrm{L}-311 \mathrm{U} / \mathrm{L})$ \\
Sodium & 135.20 & $(140.0 \mathrm{U} / \mathrm{L}-155.0 \mathrm{U} / \mathrm{L})$ \\
Potassium & 3.21 & $(3.60 \mathrm{mmol} / \mathrm{L}-5.10 \mathrm{mmol} / \mathrm{L})$ \\
Calcium & 2.14 & $(2.20 \mathrm{mmol} / \mathrm{L}-2.90 \mathrm{mmol} / \mathrm{L})$ \\
Chloride & 110.20 & $(105.0 \mathrm{mmol} / \mathrm{L}-120.0 \mathrm{mmol} / \mathrm{L})$ \\
Urea & 10.00 & $(3.6 \mathrm{mmol} / \mathrm{L}-8.9 \mathrm{mmol} / \mathrm{L})$ \\
Creatinine & 59.00 & $(40 \mathrm{umol} / \mathrm{L}-133 \mathrm{umol} / \mathrm{L})$ \\
\hline
\end{tabular}

Comments: Serum 5+ haemolysed.

fundic region there was a luminal, oval $2.9 \mathrm{~cm}$ heterogeneous structure surrounded by a $5 \mathrm{~cm}$ hyperechoic rim. This rim cast a distal acoustic shadow (Figure 1). The sagittal image showed an apparent layering within the previously described structure (Figure 2). The pyloric region was within normal limits and the rest of the gastrointestinal tract was empty. A gastric foreign body was strongly suspected. Oesophagogastric involvement could not be excluded. The stomach wall was within normal limits and no evidence of perforation or gastric wall necrosis was noted.

Survey thoracic radiographs (Figures 3 and 4) showed mild loss of cranial abdominal serosal detail with a focal soft tissue opacity in the left cranial abdominal cavity, assumed to be a fluid-filled stomach. No aortic aneurysms or thoracic 
spondylitis were noted. It was concluded that a gastric foreign body was most likely, as the evidence on thoracic radiographs did not obviously indicate a gastro-oesophageal intussusception.

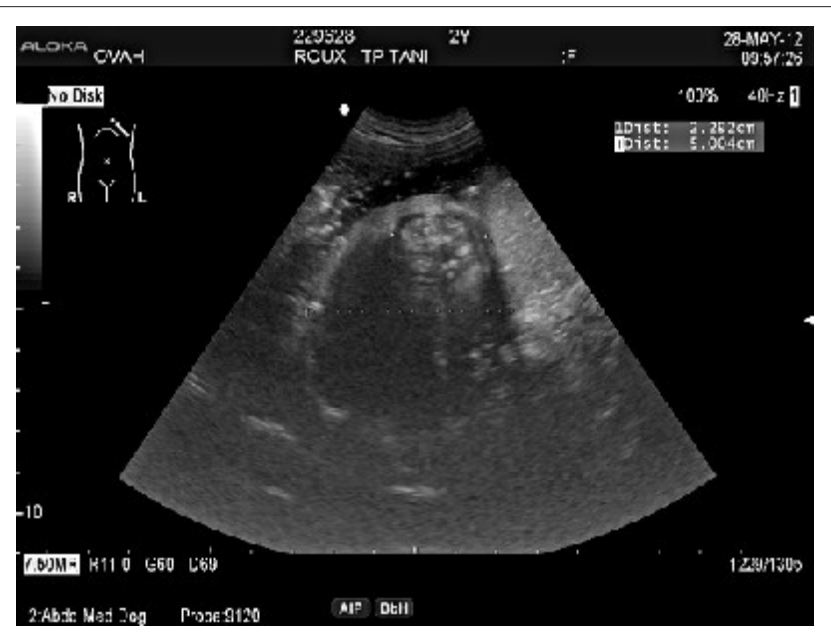

Source: Onderstepoort Veterinary Academic Hospital

FIGURE 1: Abdominal ultrasound - Cardiac region of stomach shows a luminal, oval structure, $2.9 \mathrm{~cm}$ in length with a heterogenous appearance.

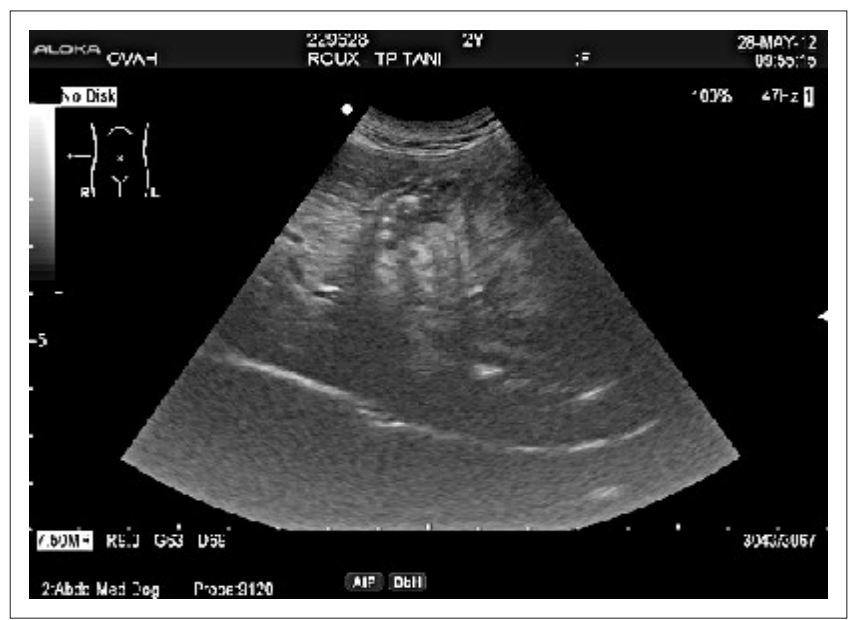

Source: Onderstepoort Veterinary Academic Hospital

FIGURE 2: Abdominal ultrasound - Sagittal view of stomach, shows a petal appearance and apparent layering of the stomach wall.

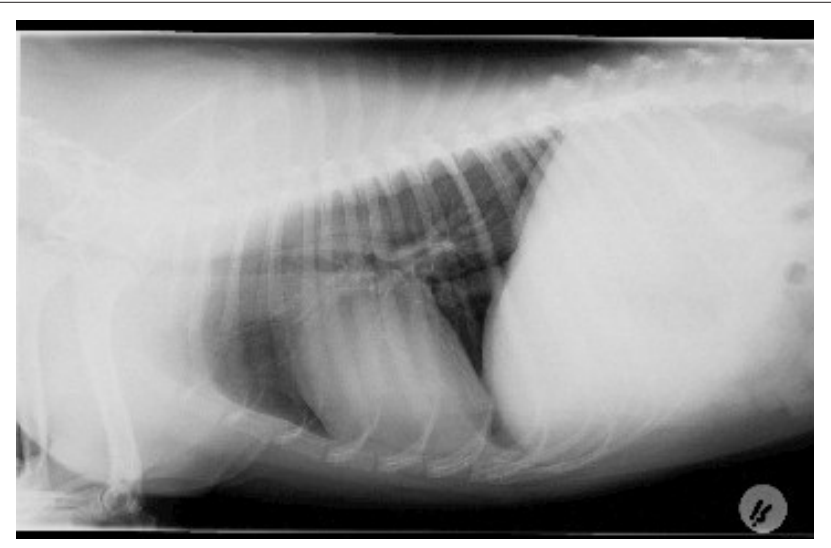

Source: Onderstepoort Veterinary Academic Hospital

FIGURE 3: Right lateral thoracic view - no signs of a caudal thoracic mass or spondylitis present.

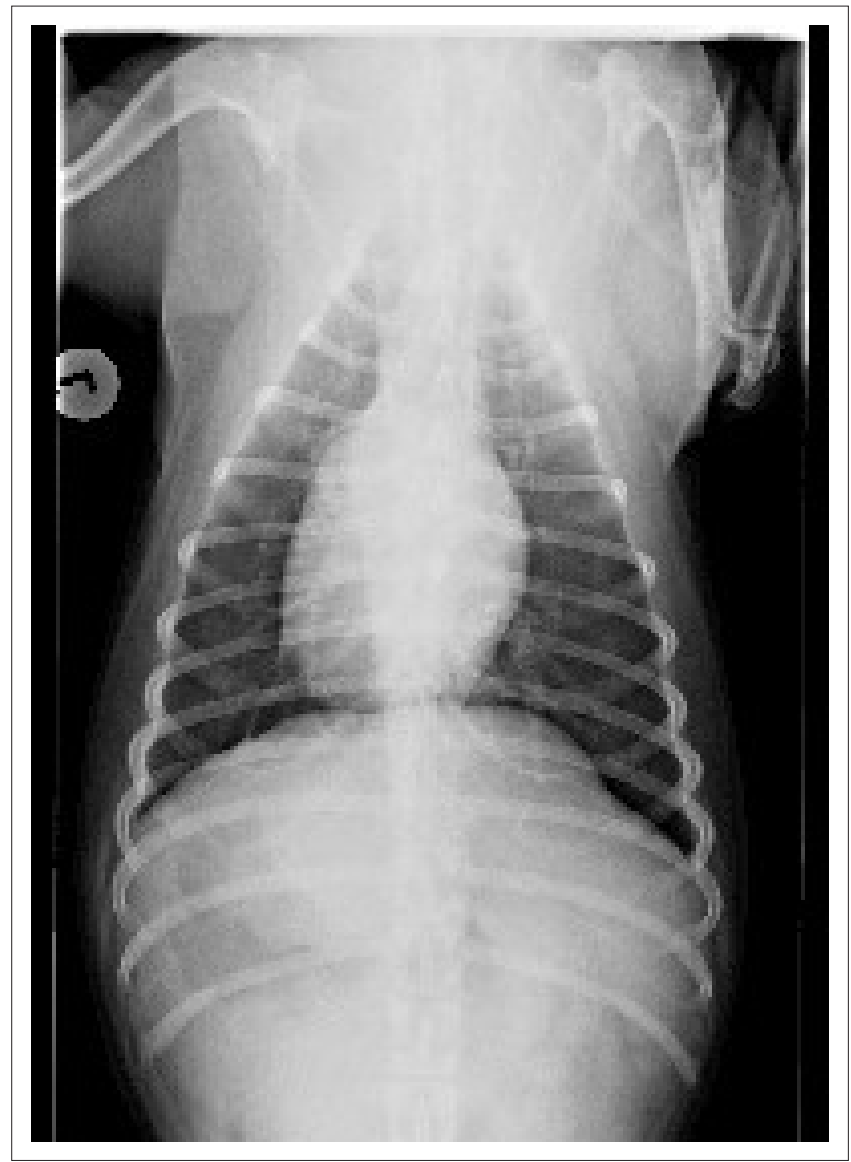

Source: Onderstepoort Veterinary Academic Hospital

FIGURE 4: Ventro-dorsal thoracic radiograph - note that there are no signs of an undulating aorta.

A gastrotomy via a midline laparotomy incision was performed. The stomach was partially filled with digested bloody fluid; no foreign body was present. The cardiac sphincter appeared enlarged and thickened and there appeared to be a smooth mass surrounding the sphincter. The surgeon did not explore the cardiac region any further, given the poor prognosis of cardiac sphincter pathology and limited funds. The owners were contacted and the dog was euthanased on the table due to cost constraints.

A post-mortem examination was conducted and there was a focal S. lupi nodule at the oesophagogastric junction with approximately $2 \mathrm{~cm}$ invagination of the distal oesophagus into the stomach. There was melaena secondary to diffuse gastrorrhagia. No macroscopic evidence of gastric thrombi or infarcts was noted. The aorta contained multifocal aneurysms.

Microscopically, the nodule consisted of worms surrounded by degenerate neutrophils, lymphocytes, plasma cells, occasional macrophages and mast cells, as well as fibrous connective tissue with mature fibrocytes and plump fibroblasts, some of which appeared embryonal. The final diagnosis on post-mortem examination was an S. lupi non-neoplastic nodule in the caudal oesophagus with an oesophagogastric intussusception. 


\section{Ethical considerations}

This article was written using data retrieved from the patient record system of the OVAH as a retrospective clinical case of a client-owned pet. The animal reported in this article was treated and housed according to the standard OVAH protocols for the management of client-owned pets. All diagnostic tests and treatments were performed as part of the treatment of the patient and routine work.

\section{Discussion}

This case was unique for a number of reasons: it was a spirocercosis case that presented as an emergency due to the presence of an oesophagogastric intussusception, which caused an obstruction and blood loss. To the best of the authors' knowledge, this is the first described case of an oesophagogastric intussusception in a dog. Gastro-oesophageal intussusceptions are rare in dogs but should be considered as a differential diagnosis in cases of unresponsive vomiting and regurgitation (Graham et al. 1998). Due to the same structures being involved in an oesophagogastric intussusception, similar presenting and clinical signs to a gastro-oesophageal intussusception could be expected, although there are obvious differences in the radiographic diagnosis. The rapid progression of clinical signs and deterioration of a patient with a gastro-oesophageal intussusception requires early diagnosis and surgical correction (Leib \& Blass 1984). Some possible predisposing factors for gastro-oesophageal intussusception include: pre-existing megaoesophagus, incompetency of the lower-oesophageal sphincter, oesophageal congenital abnormalities and vomiting (Graham et al. 1998; Leib \& Blass 1984; Rallis et al. 1995). An S. lupi nodule so close to the cardia may have produced mechanical or functional aberration of lower oesophageal tone, thus provoking lower oesophageal relaxation and invagination of the stomach into the lumen of the oesophagus (Rallis et al. 1995). Spirocerca lupi has been described as producing oesophageal neuromuscular degeneration as a result of chronic inflammation caused by the presence of the parasite and asynchronous relaxtion of the lower oesophageal sphincter (Rallis et al. 1995). It is possible in this case that the S. lupi nodule caused similar effects, but instead the oesophagus invaginated into the stomach.

The S. lupi nodule found at the cardia was not in a typical location for a mass to form. The typical location of the nodule is a few centimetres cranial to the diaphragm (Bailey 1972). In clinically affected patients, the typical oesophageal nodule will usually be seen on radiographs (Van der Merwe et al. 2008). In the majority of patients, the nodule is found in the caudal oesophagus (Dvir et al. 2001). It has been reported that $82 \%$ of the oesophageal masses were located in the caudal oesophagus (caudal to the heart base) and $18 \%$ of the cases were more cranially located (hilar region) (Dvir et al. 2001). Gastric nodules were found on necropsy in 5\% of dogs (Van der Merwe et al. 2008). The present case provided a diagnostic challenge, as the typical radiological signs of spirocercosis were not present. On examination of the thoracic radiographs, no obvious caudal oesophageal mass was present, nor was there evidence of aortic aneurysms or caudal thoracic spondylitis. Caudal thoracic vertebral spondylitis in spirocercosis is observed on radiographs in up to $53 \%$ of cases (Dvir et al. 2001; Mazaki-Tovi et al. 2002). Scarring of the thoracic aorta is a pathognomonic lesion of an S. lupi infection and aneurysms of various sizes are often present (Fox et al. 1988). Although the aneurysms, which are seen as undulations of the thoracic aorta, were not noted radiographically in this case, there was evidence of worm migration on post-mortem examination.

Faecal flotation per se is not a sensitive tool in confirming a diagnosis of spirocercosis (Christie et al. 2011; Fisher et al. 2009). Diagnosis by faecal analysis is only possible when eggs are being shed. This passage can occur for an unpredictable, relatively short period in adult worms (Fox et al. 1988). Egg shedding by S. lupi-infected dogs is variable and does not occur in all infected individuals (Christie et al. 2011). Eggs will only be present in the faeces when the female has a patent passage to the oesophageal lumen, thus, maturation of the nodule is essential (Van der Merwe et al. 2008). Faecal sedimentation has been found to be the most sensitive procedure for diagnosis of spirocercosis on faecal examination (Fox et al. 1988).

Endoscopy has been found to be the antemortal gold standard modality (Dvir et al. 2001; Kirberger et al. 2012). The mass can also be evaluated and biopsied during endoscopy (Dvir et al. 2008). Computed tomography (CT) has been found to accurately determine the exact size and shape of the mass, as well as changes to and involvement of the surrounding structures (Dvir et al. 2001). Both endoscopy and CT may have been helpful in this case, but were not deemed necessary as the thoracic radiographs were normal.

\section{Acknowledgements}

The authors would like to thank Dr Adri Steenkamp for her contribution to the post-mortem and histopathology analysis.

\section{Competing interests}

The authors declare that they have no financial or personal relationship(s) which may have inappropriately influenced them in writing this article.

\section{Authors' contributions}

K.J.V. (University of Pretoria) was the primary author who was presented with the case, assisted with the work up and reviewed and researched the case. N.C. (University of Pretoria) was the primary radiologist on the case. E.D. (University of Pretoria) was the primary small animal internal medicine clinician on the case. 


\section{References}

Bailey, W.S., 1972, 'Spirocerca lupi: A continuing inquiry', Journal of Parasitology 58, 3-22. http://dx.doi.org/10.2307/3278233

Christie, J., Schwan, E.V., Bodenstein, L.L., Sommerville, J.E.M. \& Van der Merwe, L.L., 2011, 'The sensitivity of direct faecal examination, direct faecal flotation, modified centrifugal faecal flotation and centrifugal sedimentation/flotation in the diagnosis of canine spirocercosis', Journal of the South African Veterinary Association 82, 71-75. http://dx.doi.org/10.4102/jsava.v82i2.37

Dvir, E., Kirberger, R.M. \& Malleczek, D., 2001, 'Radiographic and computed tomographic changes and clinical presentation of spirocercosis in the dog', Veterinary Radiology and Ultrasound 42, 119-129. http://dx.doi. org/10.1111/j.1740-8261.2001.tb00914.x

Dvir, E., Kirberger, R.M., Mukorera, V., Van der Merwe, L.L. \& Clift, S.J., 2008, 'Clinical differentiation between dogs with benign and malignant spirocercosis', Veterinary parasitology 155, 80-88. http://dx.doi.org/10.1016/j.vetpar.2008.04.006

Fisher, M.M., Morgan, J.P., Krecek, R.C. \& Kelly, P.J., 2009, 'Radiography for the diagnosis of spirocercosis in apparently healthy dogs, St. Kitts, West Indies', Veterinary Parasitology 160, 337-339. http://dx.doi.org/10.1016/j.vetpar.2008.11.021

Fox, S.M., Burns, J. \& Hawkins, J., 1988, 'Spirocercosis in dogs', Compendium on Continuing Education for the Practicing Veterinarian 10, 807-822.
Graham, K.L., Buss, M.S., Dhein, C.R., Barbee, D.D. \& Seitz, S.E., 1998 'Gastroesophageal intussusception in a Labrador retriever', Canadian Veterinary Journal 39, 709-711.
Jostroeso

Kirberger, R.M., Clift, S.J., Van Wilpe, E. \& Dvir, E., 2012, 'Spirocerca lupi-associated vertebral changes: A radiologic-pathologic study', Veterinary Parasitology 195(1-2), 87-94.

Leib, M.S. \& Blass, C.E., 1984, 'Gastroesophageal intussusception in the dog: A review of the literature and a case report', Journal of the American Animal Hospital Association 20, 783-790.

Mazaki-Tovi, M., Baneth, G., Aroch, I., Harrus, S., Kass, P.H., Tomer B. et al., 2002, 'Canine spirocercosis: Clinical, diagnostic, pathologic, and epidemiologic characteristics', Veterinary Parasitology 107, 235-250. http://dx.doi.org/10.1016/ S0304-4017(02)00118-8

Rallis, T., Moraitou, K. \& Vlemmas, J., 1995, 'Gastroesophageal intussusception in an adult dog', Canine Practice 20, 7-11.

Van der Merwe, L.L., Kirberger, R.M., Clift, S., Williams, M., Keller, N. \& Naidoo, V., 2008, 'Spirocerca lupi infection in the dog: A review', Veterinary Journal 176 294-309. http://dx.doi.org/10.1016/j.tvjl.2007.02.032

Von Werthern, C.J., Montavon, P.M. \& Fluckiger, M.A., 1996, 'Gastro-oesophageal intussuception in a young German shepherd dog', Journal of Small Animal Practice 37(10), 491-494. http://dx.doi.org/10.1111/j.1748-5827.1996.tb01750.x

Watrous, B.J., 2007, 'Chapter 28 Esophagus', in D. Thrall (ed.), Textbook of Veterinary Diagnostic Radiology, 5th edn., pp. 495-511, Elsevier, St Louis, Missouri. 